\title{
Orientations of dolmens in Western Europe
}

\author{
Michael Hoskin \\ St Edmunds' College, University of Cambridge, \\ Cambridge CB3 0BN, United Kingdom \\ email: michael.hoskin@ntlworld.com
}

\begin{abstract}
The communal tombs ('dolmens') constructed through Europe and the Mediterranean region in the late Neolithic nearly always had an entrance to permit the introduction of further bodies, and hence an orientation. Extensive fieldwork shows that the builders always felt constrained to observe a custom of orientation, and in most of Western Europe the custom may well have been to face the rising Sun at some time of year, or the Sun after it had risen. But at Fontvieille near Arles the local custom was quite different, with tombs facing sunset or the Sun when descending. In southwest France and neighbouring parts of Cataluña the two customs are in conflict.
\end{abstract}

Keywords. Dolmens, orientation, Western Europe, Iberia, Fontvieille, Menorca, Mallorca

\section{Introduction}

Over the last two decades the writer has conducted a campaign to visit as many as possible of the dolmens of Western Europe and the Mediterranean region, and to measure their orientations. The intention was first, to determine whether or not the orientation of the dolmen was random or whether the constructors were following a local custom; second, if they were indeed following a custom, to establish the range of orientations permitted by the custom; and third, to explore the underlying motivation that may have led to the range that we find. The orientation of a dolmen is of course only one of its innumerable features that are worthy of investigation, but it is a feature that archaeologists often neglect and, as we shall see, the study of orientations can shed important light on the purpose of the monuments.

At first encounter, the variety of forms that dolmens take is bewildering. Most are built on the surface, but a few are excavated out of the bedrock. Of those on the surface, most are megalithic, built with a small number of large stones, but some are made of large numbers of small stones, most notably the false-cupola tombs known as tholoi. Of the megalithic tombs, some are modest in size and could be built by a single family in a matter of days, others are monumental on a scale that defies belief. Most are passage graves, but the passages may be long or short. However, all these communal tombs were designed to permit the introduction of additional bodies as the need arose, and although very occasionally access was from overhead, nearly always the chamber has a well-defined entrance opposite the backstone, and therefore an orientation, the direction faced by bodies imagined as looking out through the entrance.

With rare exceptions, the passage (if any) has the same orientation as the chamber; that is, the monument as a whole has an axis of symmetry and its orientation is unproblematic. On the French Causses, however, there are a few small 'coudé' tombs in which the passage is set at an angle to the chamber (Chevalier 1999), and the same is true of a handful of major tombs in the Carnac region of Brittany (Hoskin 2007a); in these the orientation (if any) intended by the builders is unclear, although the dual directions involved are far from random. The great Breton dolmens à entrée latérale - in effect, East-facing allées 


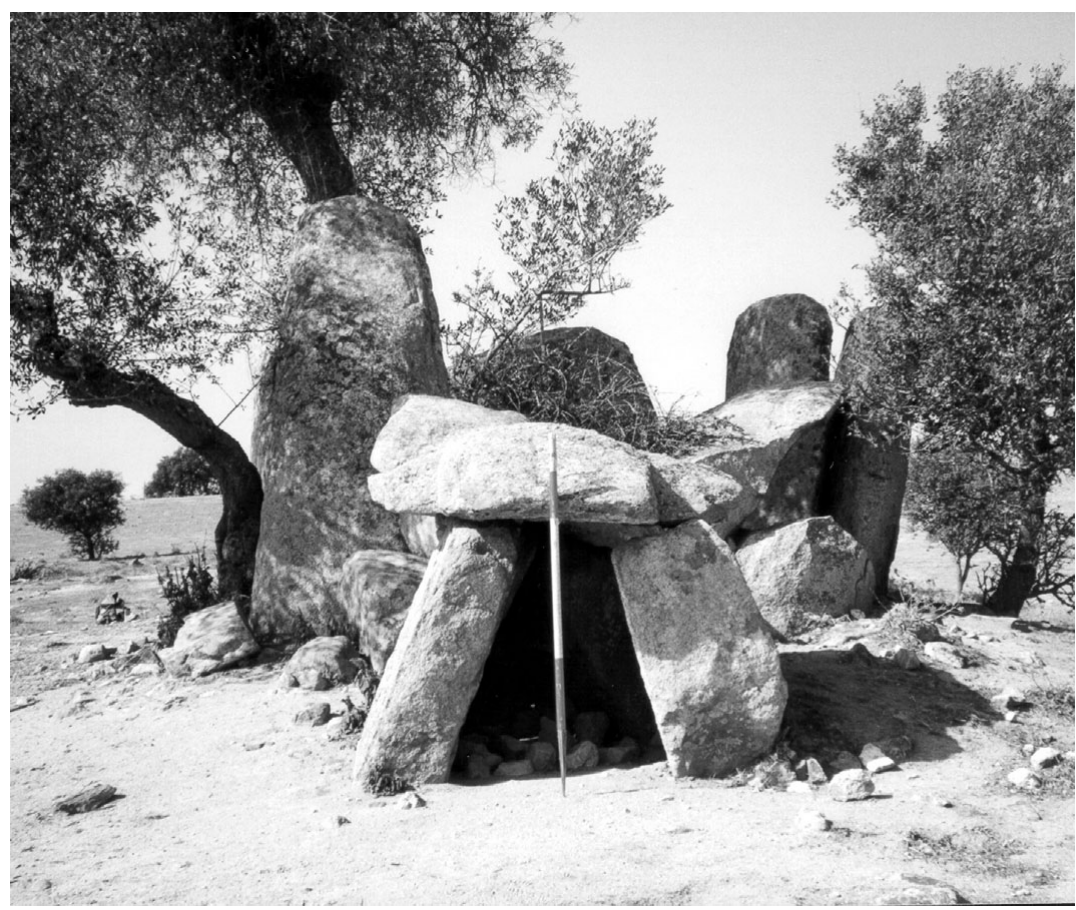

Figure 1. Caeira 2, one of the seven-stone dolmens at Mora in the Alentejo. In the foreground is the passage, and beyond we see the tall sidestones of the chamber, which originally leant inwards but which have been pushed out by the fall of the capstone. These seven-stone dolmens are among the tallest megalithic tombs of western Europe: the stones of the chamber of Anta Grande de Zambujeiro, South of Évora, are over 5 metres in height.

couvertes with the entrance located around the corner on the south side - appear at first sight to be similarly anomalous (Hoskin 2007b), but if the orientation is taken to be that of the chamber (rather than the entrance) then the dolmens conform to the overall pattern that we discuss in what follows. With these minor exceptions, the Neolithic dolmens of western and southern Europe have well-defined and uncontroversial orientations that can be measured. The first question then to be asked of any group of dolmens is, Do the orientations fall into a pattern or are they random? The great royal tholoi of Mycenae simply face downhill (Hoskin 2001), but this is most unusual. The answer, for almost all regions, all periods, and all forms of structure, is: Yes, the orientations fall into a pattern. That is, the builders almost always felt constrained to construct the tomb so that its orientation conformed to custom.

The second question is, Was the pattern we find motivated by the sky? Investigators often assume that this is the case, but this is a methodological error: the orientations of mosques display a clear pattern and we know this has nothing to do with the sky. The clearest evidence of a pattern that was certainly motivated by the sky is to be found in the seven-stone dolmens of the Alentejo region of Portugal (Hoskin 2001). These tombs are of unique construction (Fig. 1): the backstone is a true orthostat, but the three stones to each side of the backstone are not orthostats but each leans on the preceding stone. As a result the dolmens are easily recognizable and form a well-defined group. Of the 177 I have measured (Fig. 2), every single one faced within the narrow range of the eastern skyline where the Sun (and the Moon) would at times be seen to rise. 
M. Hoskin

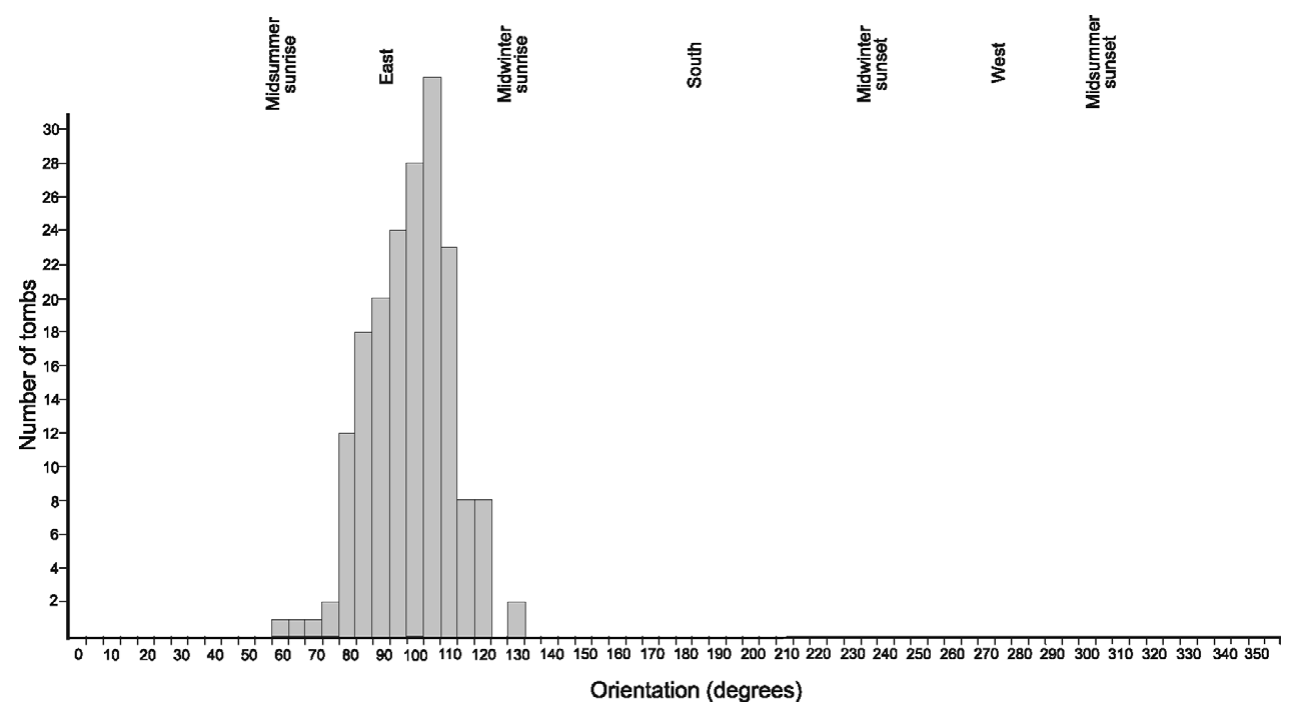

Figure 2. Histogram of 177 seven-stone dolmens of central Portugal and neighbouring Spain. Despite the great number of tombs and the vast area over which they are spread, every single one of the 177 faced sunrise (to within a couple of degrees), the majority in autumn/spring or winter.

This is extraordinary, given that the range of Sun- or Moonrise extends over only onesixth of the horizon. That this could happen by chance is out of the question, and as the tombs are scattered over a vast area of Portugal (and even into Spain), the custom of orientation cannot be terrestrial in motivation and so must be celestial. The range of moonrise extended a little further North and a little further South of the range of sunrise, and so any tombs that sometimes faced sunrise would also sometimes face moonrise. However, in the summer the would-be builders must have been preoccupied with growing food, and could turn to building work only in the autumn, when the harvest was in. Overwhelmingly, the orientations of these Alentejo dolmens do in fact face sunrise in the autumn; which strongly suggests that the builders embarked on construction in the autumn and that they aligned the tombs to face the rising Sun on the day that work started (as was not uncommon in the Middle Ages with Christian churches). The alternative hypothesis, that the tombs faced moonrise, makes it difficult, though perhaps not impossible, to explain this preference for orientations a little south of east. We therefore conclude, first, that the custom of orientation was (without doubt) celestially motivated; and second, that this custom was (probably) for the dolmen to face the rising Sun on the day building started. A tomb that is oriented within the range of sunrise I characterize as sun-rising or SR. We find that not only the seven-stone tombs of the Alentejo but the tombs throughout western Iberia are overwhelmingly SR: of the 334 tombs I have measured (Fig. 3), no fewer than $324(97.0 \%)$ faced within the range $60^{\circ}-130^{\circ}$, that is, within the range of sunrise (or marginally further south, Hoskin (2001).

In southern Spain there are other groups of tombs that are SR, although often a very few members of the group have anomalous orientations. The megalithic sepulchres of Montefrío provide one example, and the tholos tombs of Los Millares another. However, as we move further from the Atlantic seaboard where it seems the earliest tombs are to be found, the SR custom appears to be relaxed, and we find increasing numbers of tombs that face south of midwinter sunrise, that is, in directions where the sun had risen and was climbing in the sky (these I term sun-climbing or SC). In total, I have measured 945 


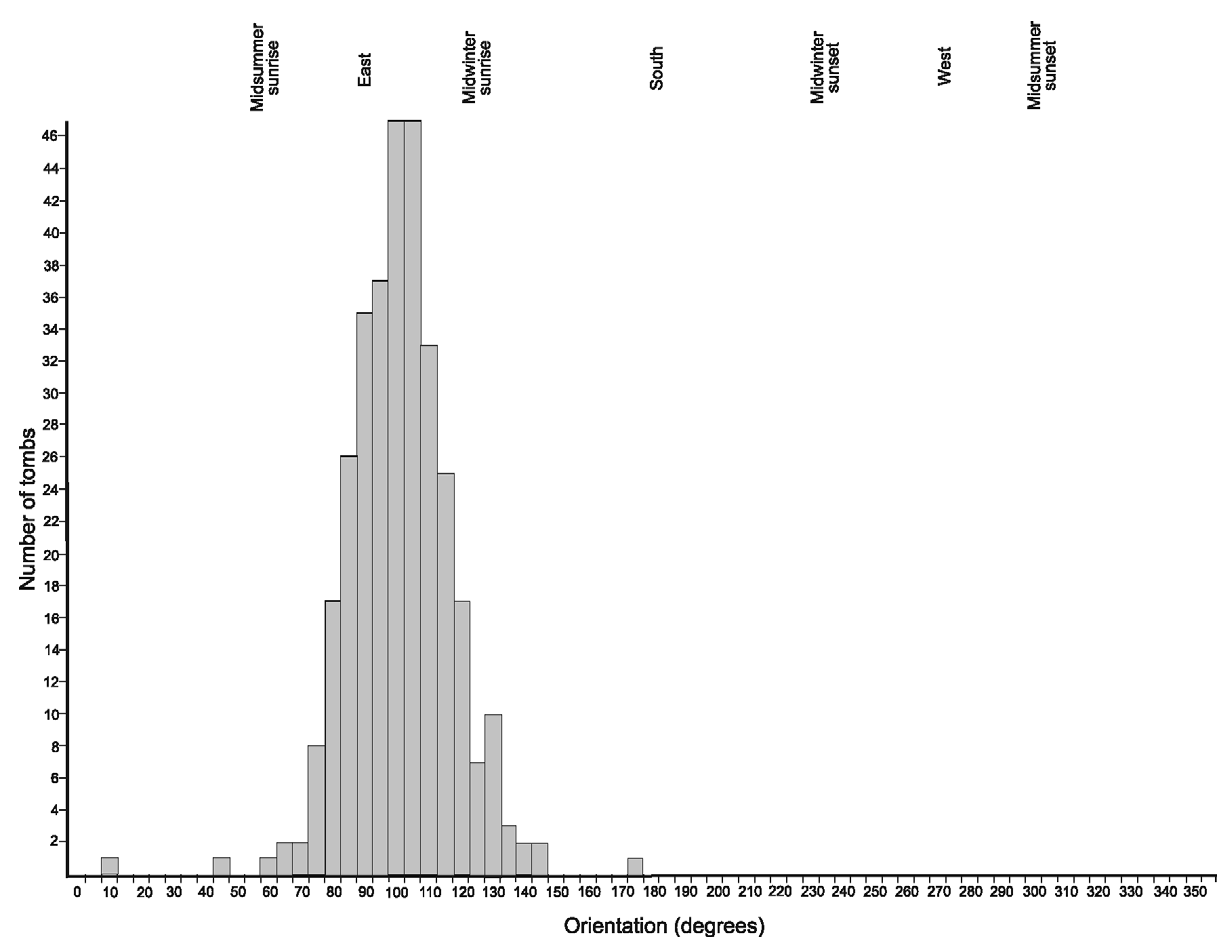

Figure 3. Histogram showing the orientations of 334 tombs of west Iberia.

tombs in Spain, Portugal and the region immediately across the Pyrenées in France, and of these no fewer than 911 (96.4\%) faced the Sun when rising or climbing (or around culmination: in the range $60^{\circ}-190^{\circ}$, SR/SC, Hoskin (2001).

Further north in France, in the Loire Valley, we encounter a wide variety of tombs, including the monumental Angevin dolmens found in greatest numbers near Angers. Every one of the 85 tombs I measured in this area faced the eastern half of the horizon. Four $(4.7 \%)$ faced anomalously north of midsummer sunrise, but the other $81(95.3 \%)$ are SR/SC (Hoskin \& Higginbottom 2002).

When we cross into Brittany in the far northwest of France, we encounter an even greater variety of tomb. There are a handful of outlying Angevin dolmens, and, along the south coast, a number of transcepted tombs, and of these a minority faced westerly (Hoskin 2003, 2007a). When we consider the much more numerous Breton passage graves and the later allées couvertes (Hoskin 2007b), it proves helpful to divide the départements of Brittany into those in the South and East (and therefore nearest the Loire), and those in the North and West. Of the 68 passage graves I have measured in the south and east, all $(100 \%)$ are SR/SC; of the 21 allés couvertes in the south and east, all $(100 \%)$ are $\mathrm{SR} / \mathrm{SC}$; while the handful of dolmens à entrée latérale in the South and East are all SR. In the north and west, however, although the majority of tombs of all types are SR/SC, a significant minority face westerly: the consensus is no longer overwhelming. In the nearby Channel Islands, all the tombs are SR (Le Conte 2008, 2009).

If we return now to the interior of southwest France, on the Causses, we find that the numerous tombs are predominantly simple dolmens, formed of just four stones: a backstone, a stone to each side, and a capstone (Chevalier 1999). Even when such a modest tomb is in pristine condition its orientation is poorly defined, and many have been disturbed over the centuries. Furthermore, our information on their orientations 
is owed mainly to (French) archaeologists, not all of whom had this datum as their primary concern. This makes the SR/SC pattern of reported orientations all the more remarkable. Every one of nearly 600 such tombs outside the southerly départements of Ardêche and Gard (of which more later) faced within the range $0^{\circ}-192^{\circ}$ : westerly (and northerly) orientations are unknown, and over $92 \%$ of the tombs faced within the range $60^{\circ}-166^{\circ}$.

This review has so far taken into account over 1700 tombs spread over Portugal, Spain, southwest, west and northwest France, the French Causses, and the Channel Islands, a vast region extending some $1500 \mathrm{~km}$ from one extreme to the other. Throughout this region, when agriculture was developed and the local clan settled in one place, people everywhere decided to build communal tombs on the surface of the ground, tombs that often seem to be dramatic statements that the land has been occupied by the clan since time immemorial; and of these 1700 tombs, nineteen out of every twenty faced sunrise or the sun when it was climbing in the sky.

Along the French Mediterranean coast, however, things were very different, and many of the tombs faced westerly rather than easterly. Working on the principle that customs become increasingly relaxed at greater distances from their source, archaeologists have pinpointed the origin of the west-facing tombs - so anomalous in the broad European context - at Fontvielle, near Arles (Sauzade 2000). The Fontvieille tombs were not prominent surface structures as in most other places; in fact, they were not surface structures at all. Instead, the long rectangular chambers were excavated out of the bedrock and then covered with roof-slabs. These slabs were carefully dressed on the interior (Fig. 4), but the exterior was left in its natural state and cannot easily be distinguished from undisturbed bedrock; only the presence of discreet entrance steps to the chamber below betrays the existence of a tomb (Fig. 5). In one place, where the rock was of poor quality, the trench was excavated as usual, and then a dolmen with drystone walls was built within it, below ground level and concealed from sight.

Not only were the tombs hidden from view, but they faced West rather than East. The number of tombs at Fontvieille is too small to permit a statistical proof, but the pattern of orientation is consistent with the tombs being constructed to face the setting Sun (sun-setting or $S S$ ). With increasing distance from Fontvieille, we find tombs that modify the structural form found there: the tombs are constructed on the surface rather than below ground, the chambers are again rectangular but less extreme in length, and the sidewalls frequently alternate the fragile drystone with vertical slabs. And just as in Iberia the strict SR custom seems to have been relaxed with increasing distance to permit directions where the sun is climbing and so became SR/SC, so the SS custom of Fontvieille seems to have been relaxed to permit directions where the sun is descending (sun-descending or SD) and so became SD/SS.

To the East of Fontvieille, throughout Provence in the direction of the Italian frontier, the tombs are uniformly SD/SS (Fig. 6) (Hoskin 2001). The influence in Provence, it seems, comes solely from Fontvieille; and this is unsurprising, because in neighbouring départements of southeast France the SR/SC tombs widespread elsewhere are nowhere to be found. But to the West of Fontvieille, as far as the Spanish frontier and a little beyond, the custom of westerly orientation was in conflict with the normal SR/SC custom found on the Causses, and there is a confusion of construction styles as well as of orientations (Hoskin\& Palomo i Pérez 1998; Hoskin \& Palomo i Pérez 1999; Iund 2002). The situation is particularly interesting in Ardêche and Gard, not far from Fontvieille. There the SR/SC tombs tend to face closer to south than usual, and the same is true of the SD/SS tombs (Fig. 6): it is as though the rival customs are seeking to downplay their differences (Hoskin 2001). 


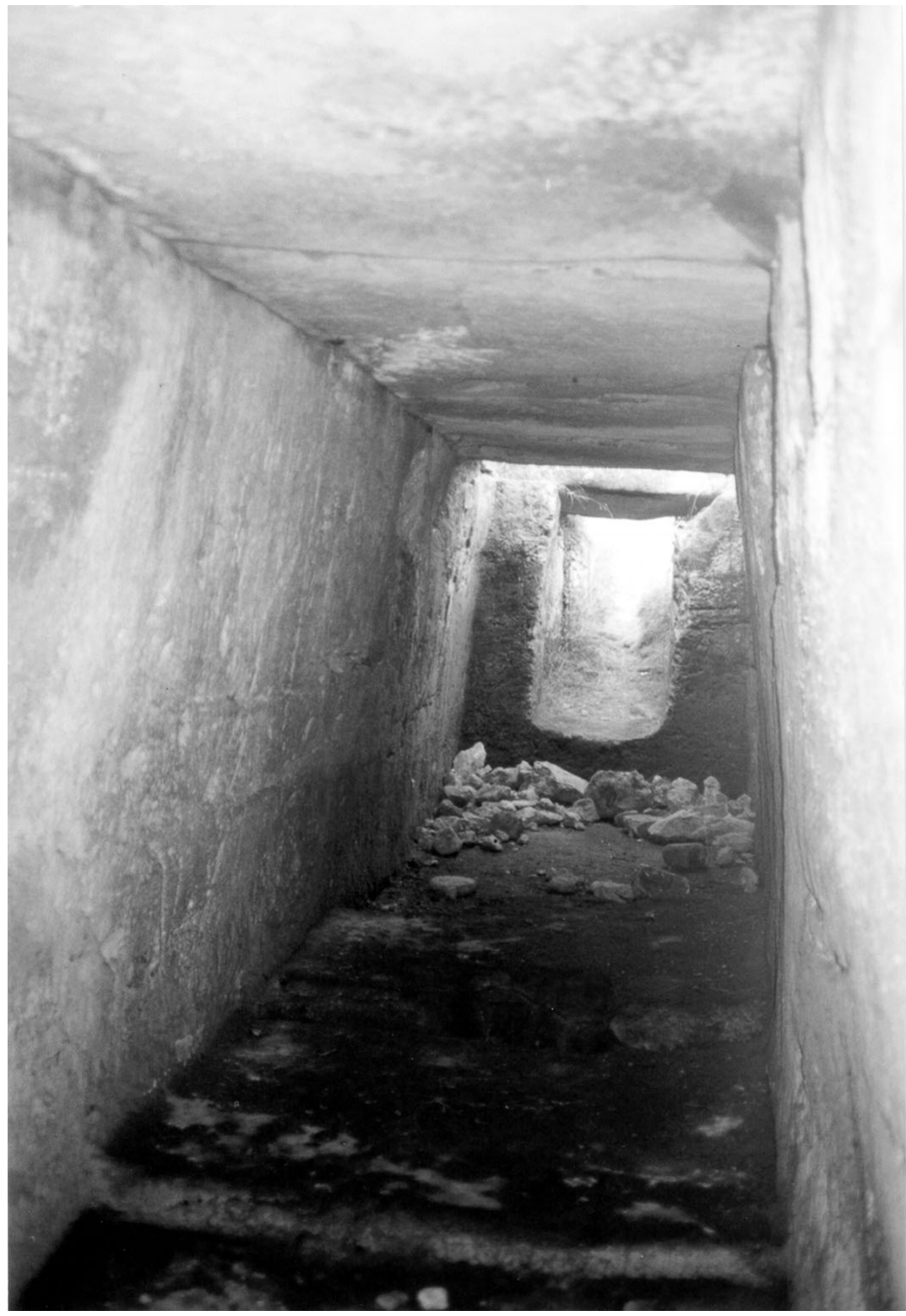

Figure 4. The interior of the dolmenic hypogeum of Le Castellet, Fontvieille. The floor, side-walls, entrance and ramp in the photograph have been excavated out of the bedrock, but the roof is formed of slabs. Note the extraordinary care with which the various components have been shaped, and the near-perfect fit between adjacent roof slabs. (Photograph by M. Hoskin).

The picture that has emerged from our fieldwork in the mainland of Europe, therefore, is of orientations to sunrise, or to the Sun when rising, throughout Iberia and the Southwest, West and Northwest of France; and to sunset, or the Sun when descending, along the French Mediterranean coast East from Fontvieille and (but only in competition) West from Fontvieille as well.

The Balearic Islands, like all islands, present a picture that is only loosely related to developments on the mainland. The earliest tombs, of which only a handful survive, are 


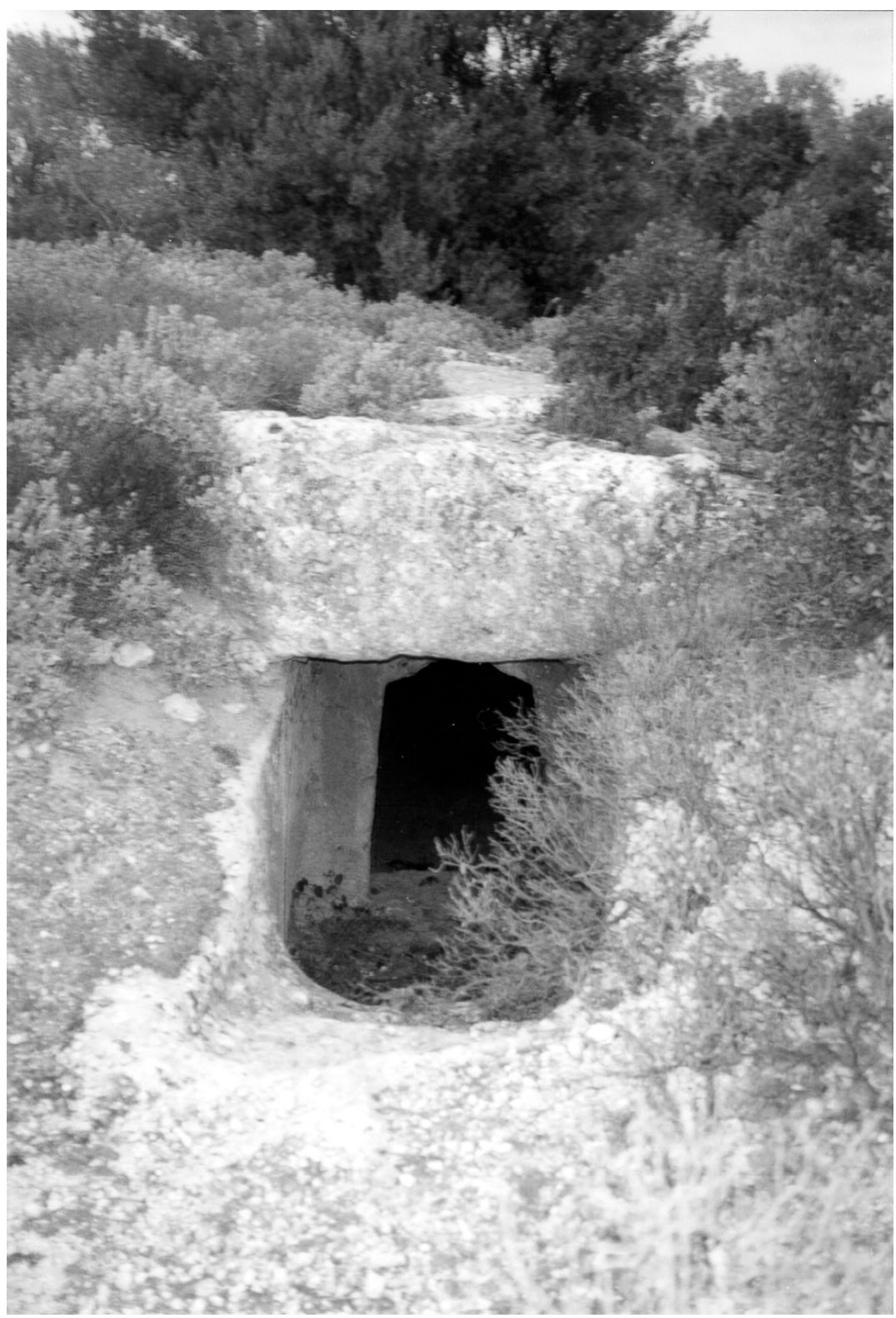

Figure 5. The ramp leading down to the dolmenic hypogeum of La Source, Fontvieille. The capstones are carefully shaped on the lower face but left in their natural state above ground. (Photograph by M. Hoskin).

small megalithic sepulchres, quite unlike the dolmens of the Fontvieille tradition, although on archaeological grounds an influence from southern France is well-established. But like the Fontvieille dolmens, they face westerly. So do the great Bronze Age navetas of the Talayotic culture, two- story structures that resemble an upturned boat and are quite unlike dolmens found anywhere else (Hoskin 2001).

This Talayotic culture is very remarkable for the numerous sanctuaries known as taulas. At the centre of a taula is a tall rectangular stone set into the bedrock, and on top of this stone is (or was) a horizontal slab, the two stones together having the appearance 


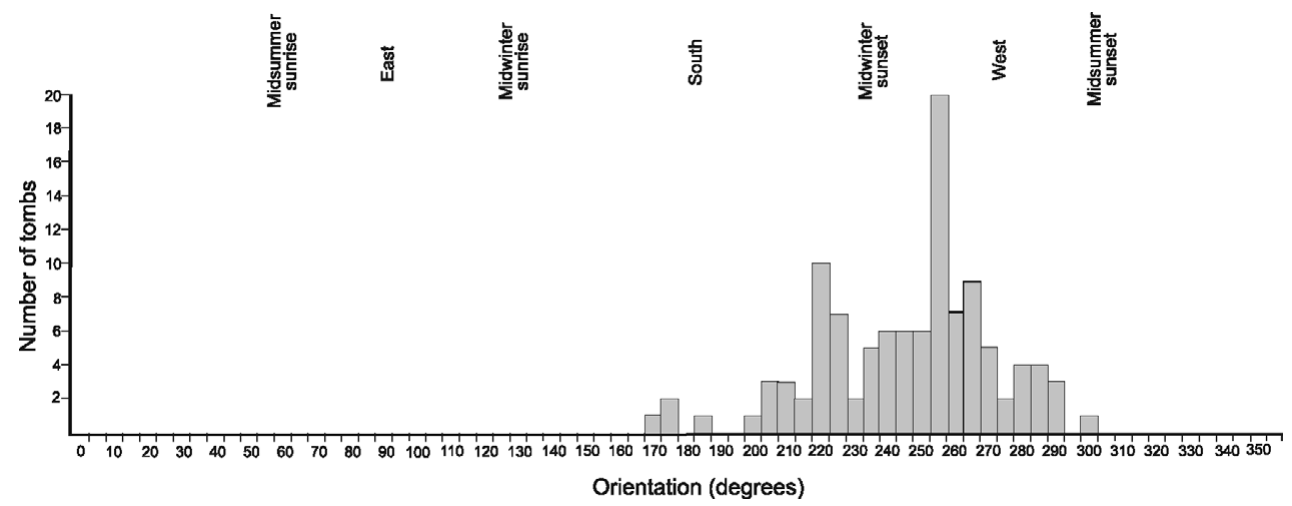

Figure 6. Histogram showing the orientations of 110 dolmens of Provence and east Languedoc. The five tombs with azimuths closest to due South are all in Ardêche.

of a capital letter T (Fig. 7). This central feature is surrounded by a complex precinct wall, with an entrance that faces the central feature. The central feature therefore looks out through the entrance, and so the taula has a well-defined orientation.

With one exception, the thirty or so taulas all face southerly, roughly between Southeast and Southwest. Significantly, all these taulas have a perfect view of the Southern horizon: either they look directly out to sea, or they are on elevated ground and look down over a plain. This cannot have happened by chance, and so we must ask what it was, close to the southern horizon, that the taulas were facing. There is no land in that direction, and today there is nothing in the sky that is of any interest. But the sky to the South that we see today is very different from the sky that was visible in Talayotic times. The Earth is not a perfect sphere, and as a result the gravitational pull of the Sun and Moon on the Earth causes the Earth's axis to wobble. Calculation shows that the Talayotic people could see, rising out of the sea a little East of South, the star group of the Southern Cross and Alpha and Beta Centauri, a group that is striking enough to be featured today on the national flags of Australia and New Zealand; and this must surely be the object to which the taulas faced (Hoskin 2001).

One can speculate as to why these stars were significant. The excavators at the taula of Torre d'en Gaumes discovered a small bronze statue of a seated man with an inscription in Egyptian hieroglyphics that declared the man to be Imhotep, the god of medicine. Now although the early history of the constellations in the Mediterranean is confused, in Greek mythology the star group was part of the constellation named after the Centaur (Chiron) who taught medicine to Asclepius, the Greek god of medicine. It may well be that this taula, and perhaps all taulas, were associated with healing, and that a passing Egyptian sailor discovered this and decided to deposit there his statue of his god of medicine.

In Mallorca too there was a Talayotic culture, but no taulas such as one finds on Menorca. Menorca is very flat, and from almost every Talayotic village it would have been possible to find somewhere a location that gave a good view to the south and the Southern Cross. But Mallorca is mountainous, and if taulas were indeed intended to face this Cross, this would explain their absence from Mallorca. A remarkable example of the merit of collaboration between investigators with different skills occurred in 1998, when a team of archaeologists from the popular British television series Time Team visited the Son Mas site near Valldemossa in the North of Mallorca. The site had been excavated by the late William Waldren, and he had found there an Iron Age sanctuary. Near the sanctuary he discovered surprising quantities of high-quality pre-talayotic pottery, and 


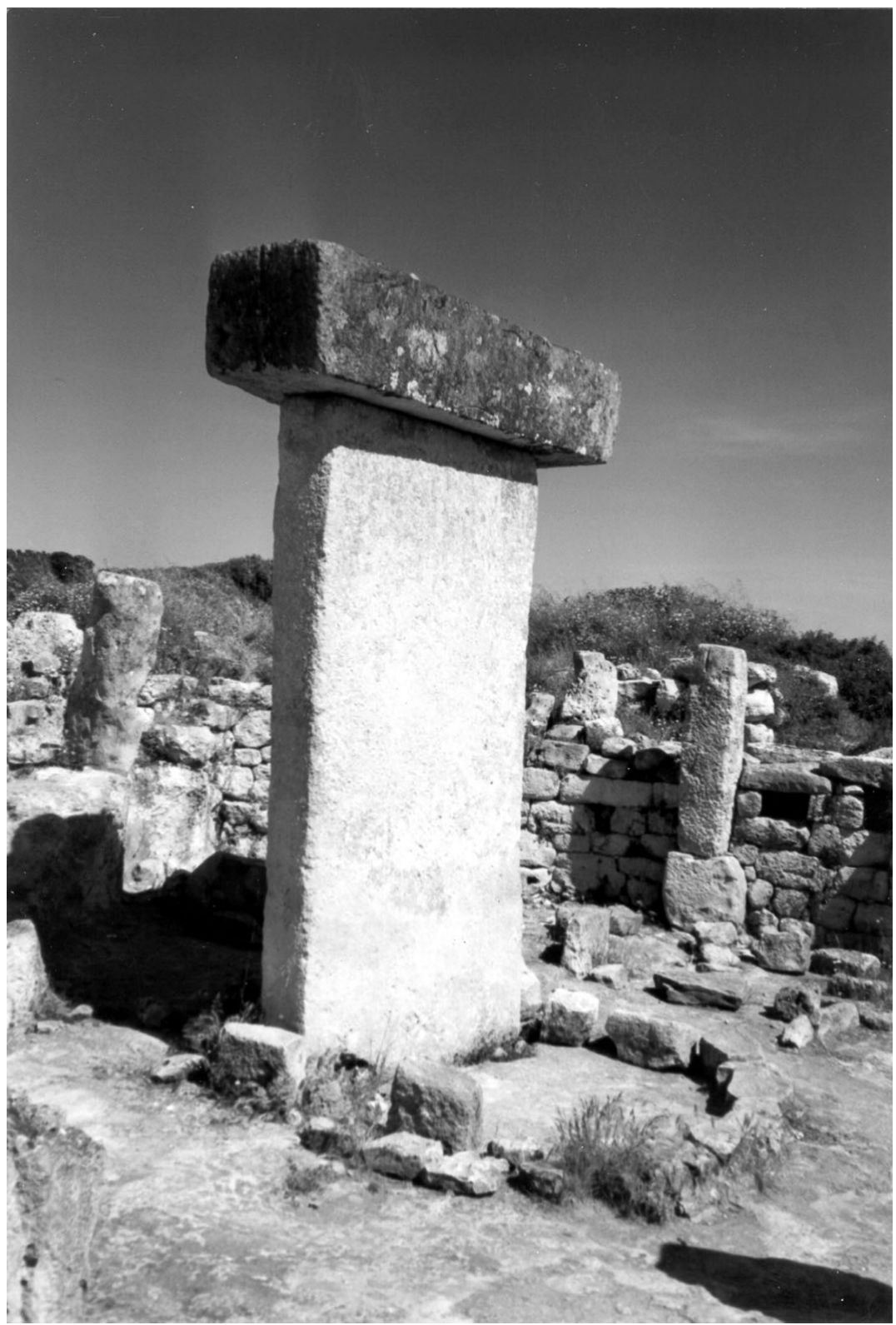

Figure 7. The taula of Torralba, the masterpiece of talayotic architecture. The precinct wall survives to a height of some 1.5 metres, and many of the pilasters are present. The small stone pedastal to the left of the taula originally supported a bronze statue whose hooves (set in lead) were recovered by the excavators. (Photograph by William Waldren).

this led him to conclude that the site was already used as a ritual area in Chalcolithic times. Furthermore, outside the Iron Age sanctuary was a boulder in which there was a groove which Waldren was convinced was artificial, and which looked south down a valley (Fig. 8).

I was invited by the Time Team to measure the groove, and I found that it would have looked towards the Southern Cross when it appeared in the valley, between two hills, some two thousand years before Christ. Because of the movement of the axis of 


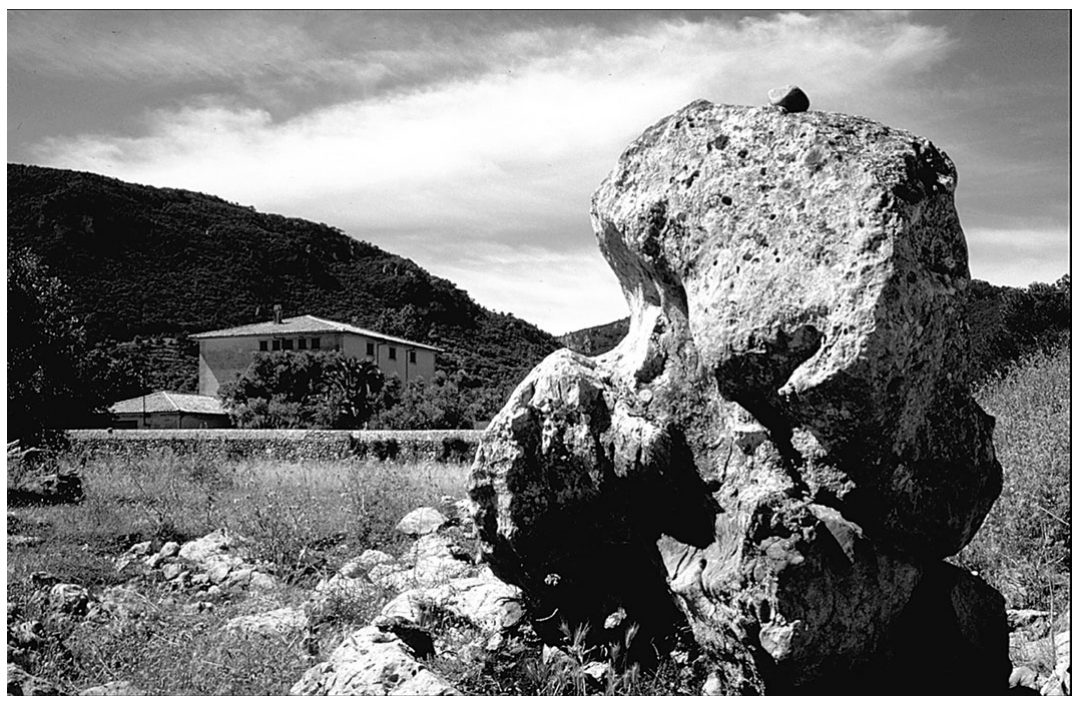

Figure 8. The boulder in front of the Son Mas sanctuary, with the valley beyond.

(Photograph by Mark Van Strydonck).

the Earth, the Cross would each year have appeared lower and lower in the sky, until around 1700 BCE. the bottom star of the Cross would have become invisible. If the groove was indeed looking toward the Cross (as I suspected because of my investigations in Menorca), then presumably there would have been a crisis around 1700 BCE. But there seemed no prospect of demonstrating any such crisis. However, Time Team had also invited Mark Van Strydonck, a Belgian specialist in radiocarbon dating. Unknown to me, Waldren and Van Strydonck had been publishing papers listing the dates of finds from the region of the sanctuary, and they had found it impossible to explain a total absence of dates from the centuries immediately after 1700 BCE. It looked as though the site had been abandoned, but they could not imagine any reason why this might have happened.

It chanced that I confided to Van Strydonck my suspicion that the occupants of the site might have experienced a crisis around $1700 \mathrm{BCE}$, and he was astonished to find me offering him the motive for site-abandonment for which he had been looking. Next day we were able to present on television the scenario we had arrived at. It was one that had involved the collaboration of an archaeologist, a radiocarbon scientist, and an archaeoastronomer (Van Strydonck, Waldren \& Hoskin 2001).

\section{References}

Chevalier, Y. 1999, France. Journal for the History of Astronomy, 30, S47

Hoskin, M. 1989, The southern taulas. Journal for the History of Astronomy, 20, S117

Hoskin, M. 1992, Journal for the History of Astronomy, 23, 57

Hoskin, M. 2001, Tombs, Temples and Their Orientations: A New Perspective on Mediterranean Prehistory (Bognor Regis: Ocarina Books)

Hoskin, M. 2002, Journal for the History of Astronomy, 33, S75

Hoskin, M. 2003, Journal for the History of Astronomy, 34, 401

Hoskin, M. 2007a, Journal for the History of Astronomy, 38, 487

Hoskin, M. 2007b, Journal for the History of Astronomy, 38, 493

Hoskin, M., Allan, E., \& Gralewski, R. 1994, Journal for the History of Astronomy, 25, S55

Hoskin, M., Allan, E., \& Gralewski, R. 1995a, Journal for the History of Astronomy, 26, S29 
Hoskin, M., Allan, E., \& Gralewski, R. 1995b, Journal for the History of Astronomy, 26, S41 Hoskin, M. \& Higginbottom, G. 2002, Journal for the History of Astronomy, 33, S51

Hoskin, M., Hochsieder, P., \& Knosel, D. 1990, Journal for the History of Astronomy, 21, S37

Hoskin, M. \& Morales Núñez, J. J. 1991, Journal for the History of Astronomy, 22, S15

Hoskin, M. \& Palomo i Pérez, T. 1998, Journal for the History of Astronomy, 29, 63

Hoskin, M. \& Palomo i Pérez, T. 1999, Journal for the History of Astronomy, 30, S80

Hoskin, M. \& Sauch i Aparicio, C. 1999, Journal for the History of Astronomy, 30, S35

Hoskin, M. et al. 1998, Journal for the History of Astronomy, 29, S39

Hoskin, M. et al. 2001, Journal for the History of Astronomy, 32, S45

Iund, R. 2002, Journal for the History of Astronomy, 33, S21

Le Conte, D. 2008, Journal for the History of Astronomy, 39, 497

Le Conte, D. 2009, Journal for the History of Astronomy, 40, 217

Ruiz, A. G. \& Hoskin, M. 2000, Journal for the History of Astronomy, 31, S41

Sauzade, G. 2000, Journal for the History of Astronomy, 31, S1

Van Strydonck, M., Waldren, W. H., \& Hoskin, M. 2001, Archaeoastronomy: The Journal of Astronomy in Culture, 16, 38 